\title{
Article
}

\section{Referrals and Child Protection in England: One in Five Children Referred to Children's Services and One in Nineteen Investigated before the Age of Five}

Bilson, Andrew and Martin, Katie

Available at http://clok.uclan.ac.uk/14881/

Bilson, Andrew and Martin, Katie ORCID: 0000-0002-7867-924X (2016)

Referrals and Child Protection in England: One in Five Children Referred to Children's Services and One in Nineteen Investigated before the Age of Five.

The British Journal of Social Work, 47 (3). pp. 793-811. ISSN 0045-3102

It is advisable to refer to the publisher's version if you intend to cite from the work. http://dx.doi.org/10.1093/bjsw/bcw054

For more information about UCLan's research in this area go to http://www.uclan.ac.uk/researchgroups/ and search for <name of research Group>.

For information about Research generally at UCLan please go to http://www.uclan.ac.uk/research/

All outputs in CLoK are protected by Intellectual Property Rights law, including Copyright law. Copyright, IPR and Moral Rights for the works on this site are retained by the individual authors and/or other copyright owners. Terms and conditions for use of this material are defined in the policies page. 


\title{
Measuring Referral and Child Protection in England: One in every five children referred to children's services and 1 in 19 investigated before the age of five
}

\begin{abstract}
Based on a Freedom of Information request with data from $75 \%$ of all English children's services departments covering over $1 / 2$ million children, this paper shows that $22.5 \%$ of children born in the 2009-10 financial year were referred to children's social care before their fifth birthday. Three-quarters of them were at some point assessed; almost two-thirds found to be in need; and a quarter formally investigated. These findings show the full extent of children's involvement in children's social care before the age of five. One in every 9 children born in 2009-10 was suspected by social workers of being abused and this high level of involvement is only justifiable if it is demonstrably reducing harm and promoting well-being of children - an outcome which is contested. Early Help's introduction was associated with high proportions of children being referred and assessed and rapidly increasing numbers of investigations thus questioning its ability to prevent entry to the child protection system. The paper calls for a change from the current emphasis on individualised and investigative approaches to child protection in order to provide an effective and humane response to children, the majority of whom live in families affected by high levels of deprivation and poverty.
\end{abstract}

Key words: Child Protection; Child Abuse; Early Help; Longitudinal; Neglect; Referral 


\section{Introduction}

Despite statistics on safeguarding being collected in England for many years, numerous inquiries, and decades of research there has never been information published at a national level to show how many children are involved in the system over their lifetime. This paper reports on a freedom of information (Fol) request that gathered data from $75 \%$ of all local authorities (LAs) in England covering over half a million children, $80 \%$ of all those born in the 2009-10 financial year. It provides, for the first time, information on how many children were referred to children's services before reaching the age of five. It also shows how many were formally assessed; suspected of abuse; subject to a child protection investigation; on a child protection plan; and entered care. More than one in five of all children were referred and many progressed deeper into the formal child protection system. Given the shame and fear that accusations of abuse can cause (Gibson 2013) this high level of involvement is only justifiable if it is demonstrably reducing harm and promoting well-being of children - a goal which is certainly contested (Edwards et al., 2015; Featherstone, White and Morris, 2014a; Frost and Parton, 2009; Gilbert et al., 2012).

The Fol request shows that this information on numbers of children involved in the safeguarding system over 5 years is easily produced. The fact that such important information has, until now, been unavailable is an indication of how research agendas and policy making in many cases have been forged either in the glare of publicity or from a focus on the worst cases, rather than based on a firm understanding of how the system operates as a whole. 


\section{Background}

The longstanding concern about over-intervention in the child protection system was strongly voiced in the 1990s in a summary of government funded research which identified as central:

the criticism that many investigations are undertaken, many families are visited and case conferences called but that in the end, little support is offered to the family. In such situations, it is unsurprising that participants become angry, alienated and bewildered. Furthermore, the children are not helped and a chunk of valuable child care resource has been consumed with little apparent benefit (DoH, 1995, pp. 54-55).

Because of the harm done to families by suspicion of abuse, the report went on to call for a change in the balance between section 47 enquiries into a child suspected of or suffering significant harm (hereafter investigations) and family support by reducing the number of children investigated and increasing the numbers receiving support. Concerns continue to be voiced about the level of investigations (Featherstone, White and Morris 2014a, b; Peckover, 2014) and a too strong focus on risk management and incidents of harm rather than help (Hayes and Spratt, 2014; Parton, 2014). The Munro Review (Munro, 2011) also called for a greater focus on Early Help to reduce abuse and neglect.

\section{Child Protection Process}

The statutory guidance on safeguarding children (DFE 2015a p.15) requires the publication of local thresholds for assessment and intervention for early help and referral for assessment for statutory services from children's social care (CSC). The London Children's Safeguarding Board's [LCSB] (undated p.6) threshold document suggests four levels of need: 
1. No additional needs: where all the child's health and developmental needs are met by universal services such as health and education;

2. Early help: where children have additional needs and/or "are showing early signs of abuse or neglect" (LCSB undated p.6). Children receive a multi-agency assessment and their needs are met by universal or targeted services not including CSC;

3. Children with complex multiple needs: this is the threshold for children to be referred to and assessed by CSC under section Section 17 because "children require specialist services in order to achieve or maintain a satisfactory level of health or development or to prevent significant impairment of their health and development and/or who are disabled" (LCSB, undated p.6);

4. Children in acute need: these children have more complex needs and meet the criteria for an investigation that there is: "reasonable cause to suspect that a child ... is suffering, or is likely to suffer, significant harm".

The statutory child protection process starts with a referral to CSC (see figure 3 ). Anyone with a concern about a child's well-being can make a referral. Some referrals do not meet the statutory threshold for assessment by CSC and are directed into universal services or Early Help. Referrals that appear to be at level 3 or 4 move to assessment. Where there is a suspicion that the child is suffering or likely to suffer significant harm (i.e. level 4) a strategy discussion (an interagency consultation involving the police) is held to decide if an investigation under section 47 is needed. Where the investigation finds that the child is suffering or likely to suffer significant harm a child protection conference is held to bring together: 
2

family members (and the child where appropriate), with the supporters, advocates and professionals most involved with the child and family, to make decisions about the child's future safety, health and development. (DFE 2015a p. 41)

Where further action is needed, the Child Protection Conference makes a child protection plan to ensure the child is safe; promote the child's health and development; and support the family in doing this.

\section{Figure 1 about here}

Involvement in child protection investigations places considerable stress on parents (Ghaffar et al., 2012) even where there is a good relationship with the social worker and the investigation finds that there has been no abuse (Davies, 2011). During much of the five year period covered by the Fol request, the safeguarding policy attempted to reduce statutory assessments and investigations through provision of Early Help and the Common Assessment Framework. The national statistics show that instead of a reduction there was a rapid increase in investigations. Figure 1 shows that child protection investigations increased by $79.4 \%$ between 2009-10 and 2014-15 (DfE, 2015a) whilst the number of referrals to LA children's services $(+5.3 \%)$ and children in need $(+6.8 \%)$ were little changed. Thus, despite the increasing focus on Early Help there was a rise from 89,300 to 160,200 investigations a year. A higher proportion of referred children (14.8\% in 2009/10 increasing to $25.2 \%$ in $2014 / 15$ ) and children in need (from $23.6 \%$ to $39.7 \%$ ) were investigated. Whilst there was an increase in children placed on a child protection plan (40.4\%) over this 6 year period, the much larger increase in investigations meant that the number of children who came under suspicion and were investigated but were not found to be significantly harmed more than doubled from 45,000 to 98,000 . In 2014-15 it is likely that less than 2 in every 5 
investigations led to a child protection plan. Whilst there is a duty to make arrangements for "step down" for children in this situation to receive Early Help, the effectiveness of these arrangements to improve the well-being and reduce the need for statutory interventions is unclear. There are no statistics on the numbers of children moving from an investigation to support services; few of the arrangements made by agencies for Early Help have been evaluated on outcomes for children (Luckock et al., 2015); and an Ofsted (2015) audit found that opportunities to help children were missed. However it has been found that parents frequently rejected voluntary support following an investigative response to referral (Thorpe et al., 2012). This increasing trend, in which over $60 \%$ of investigations do not find that children are suffering or likely to suffer significant harm, is increasing the stress on and causing harm to a growing number of families and simultaneously reducing the likelihood that these children receive help.

\section{Figure 1 about here}

\section{Figure 2 about here}

This trend of an increasing involvement of children in the child protection system is seen in a number of countries (Bilson et al., 2015; Munro and Manful, 2012) where the broadening of criteria from maltreatment to responding to children's well-being leads to more investigations (e.g. Trocmé et al., 2014; Bilson et al., 2016) and children entering state care (Gilbert et al., 2011; Bilson et al., 2016). Trocmé et al. (2014) found that over a ten year period the rate of urgent child protection referrals (any abuse of children aged under 5 , physical abuse requiring medical attention, or sexual abuse) were unchanged, whilst investigations because of concerns about the well-being of children, often because of concerns about neglect and emotional abuse, more than doubled. A similar pattern is seen 
in England where between 2009-10 and 2014-15 (DfE, 2015b) the numbers on child protection plans because of neglect $(+28 \%)$ and emotional abuse (+54\%) grew sharply whilst physical abuse fell and sexual abuse changed little (figure 2). The number of children in care also increased by $7.9 \%$ between $2009-10$ and $2014-15$ alongside the $93.4 \%$ increase in children adopted or placed in special guardianship.

Bywaters et al. (2014a p.7), in a large study in the West Midlands, found that $40 \%$ of children in care or on a child protection plan lived in communities in the $10^{\text {th }}$ decile of deprivation (i.e. the $10 \%$ of the population who are most deprived) and $60 \%$ in the $9^{\text {th }}$ and $10^{\text {th }}$ decile. There was a clear dose-response relationship between measures of deprivation and being in care or on a child protection plan and those in the $10^{\text {th }}$ decile of deprivation were around 11 times more likely to be on a child protection plan or in care than those in the least deprived decile.

There is much written about the harm caused by neglect and emotional abuse (e.g. Gould et al., 2012; Norman et al., 2012) and there are increasingly 'now or never' calls for urgent, early intervention such as Brown and Ward's (2012) paper for the judiciary. Wastell and White (2012 p. 400) show how these calls misinterpret the neuroscientific evidence on which they are frequently based. Further Edwards et al.'s research demonstrates the rhetorical use of this misinterpreted neuroscientific 'evidence' made by policy makers and practitioners (2015 p.167) that leads to "justifying gendered, raced and social inequalities" policy responses that are "positioning poor mothers as architects of their children's deprivation" (see also Featherstone et al., 2014b). Most officially recognised neglect and emotional abuse occurs in the context of poverty and investigative responses place blame on parents without reference to the role poverty plays in creating the conditions that 
reduce the ability to parent well (Bywaters et al. 2014a). Additionally, the evidence on individualised interventions to prevent further neglect and emotional abuse is sparse (Glaser et al., 2012). MacMillan et al. (2009, p. 250) state: "no intervention has yet been shown to be effective in preventing recurrence of neglect" and "there are currently no known approaches to prevent emotional abuse or exposure to intimate-partner violence". Like Mikton, and Butchart, (2009 p.1) they note a few interventions which show promise for helping children overcome the effects of neglect or emotional abuse but these findings are tentative due to methodological shortcomings of the reviews and outcome evaluation studies. This raises the question of whether increasing investigations followed by individualised interventions which necessarily involve an imbalance of power and parental blame, is the best response to the majority of neglect and emotional maltreatment (Barnard and Bain, 2015; DoH, 1995; Edwards et al., 2015; Featherstone et al., 2014 a,b; McDonell et al., 2015).

\section{Longitudinal studies}

Internationally there are few longitudinal studies of involvement in child protection and only one in England (Sidebotham et al., 2002). This study of children born in 1991-92 had a number of limitations including voluntary enrolment in the sample which led to an underrepresentation of poorer families and the sample being from a single LA. It found that $2.0 \%$ of the children were recorded as being statutorily investigated before their sixth birthday and $0.8 \%$ placed on the child protection register. Across Australia statistics from client information systems and longitudinal studies have shown referral rates to the child protection system before the age of 18 to be around 1 in 4 children in New South Wales, Queensland and Victoria (Scott, 2014 p. 16) with the lowest published ratio being 1 in 8 in 
Western Australia (Bilson et al., 2015). A study undertaken in California (Magruder and Shaw, 2008, p. 178 ) found that $19.8 \%$ of children were reported before the age of 7 . These high figures show how examining annual rates gives little indication of the huge extent of involvement in the child protection system.

\section{The Freedom of Information request}

The Freedom of Information (Fol) request was sent to all 152 English LAs in mid-2015. It requested data that is collected for the national statistics on the cohort of children born between $1^{\text {st }}$ April 2009 and $31^{\text {st }}$ March 2010 (hereafter 2009-10). Questions were based on categories from the national children in need survey which commenced in 2009 as this is a format used in client information systems across the country. A copy of the Fol request is available from the internet (http://bilson.org.uk/foi).

\section{The FoI responses}

Out of 152 English LAs, 7 did not reply and 31, for various reasons, supplied no data. Thus 114 (75.0\%) provided some or all of the data. Throughout this paper, Office for National Statistics (2016) Mid-year Population Estimates for children aged 0 or 1 on $30^{\text {th }}$ June 2010 ( $75 \%$ of those aged 0 and $25 \%$ aged 1 ) are used as a proxy to calculate the number of children in each LA in the $2009-10$ cohort. The total population of the $2009-10$ cohort in the 114 LAs was 527,550 (79\% of children in England). Whilst most LAs could answer all the questions, there was an error in the initial round of requests for data and the categories of need concerning low income and absent parenting were missed from the question list. In later requests these were included and answered by 25 LAs for low income (16.4\%) and 21 for absent parenting (13.8\%). Only 70 LAs could provide information on the number of 
children who had been placed on a supervision order and other questions were answered by at least 99 LAs.

It is the duty of a LA responding under Fol to ensure no data is provided that can identify an individual. In some cases the response to a particular question concerned a small number (usually under 5) of children and here the LAs mainly applied the good practice of indicating this and not producing the actual figure.

\section{Issues and limitations}

In reporting on the Children in Need census the Department for Education (DfE) gives an indication of the quality of responses from LAs based on: the quality of the data received; whether the LA reports issues of data quality in their return; and year on year comparisons. A 3-point scale is used with 3 indicating the highest quality. In the most recent report (DfE, 2015b) out of 152 LAs one did not provide data on referrals; three were given a rating of 1; thirty a rating of 2 ; and the majority $118(78.1 \%)$ received the highest rating of 3 . Similar scores of quality are given for other elements of the data. Thus the DfE recognise that there is some variation in the quality of this data but that the majority is of the highest quality.

In the responses to the $\mathrm{FOI}$ request there were some data returns that seem particularly high and others that were very low when compared to other results and taking into account the national statistics. It was not possible to identify if these 'outliers' were incorrect data. For example four LAs (Islington, Liverpool, Luton and North Yorkshire) provided data showing above $50 \%$ of children had been referred. Islington and Liverpool had reported high rates of referrals in their annual data and a high proportion of their population live in the most deprived areas in the country. In contrast Luton and North Yorkshire are considerably 
lower on both these measures and seem on this basis to be more likely to be erroneous. There are similar issues at the other end of the scale where nine LAs had a much lower than average proportion of children referred and the Fol data differed markedly from data reported for annual referrals. Interestingly 7 of these 9 LAs also had a quality rating of 2 for their data in 2014. Excluding these 'outliers' lowered the average rate of children referred before the age of 5 reported below by less than $2 \%$ to $21.82 \%$.

Because FOI requests can be refused if the time to create the response is excessive, the authors chose not to ask for information to be disaggregated by gender or ethnicity even though other research (Bywaters et al., 2014a, b) has shown that there are certainly differences in engagement with the child protection system when ethnicity is taken into account.

The data focusses on official reactions to child protection and does not indicate levels of actual abuse of children. Additionally, whilst there have been attempts at a national level to rationalise practice, there are large differences in decisions about what is recorded as a referral or an investigation (Platt and Turney, 2014).

\section{The Freedom of Information Request results}

The results of the Fol request are summarised in table 1 . Items in the table numbered 1 to 10 provide summaries of answers to questions of the form "Had the child at any time before his or her $5^{\text {th }}$ birthday been ..." The primary need codes (N1 to N8) record the main reason why a child started to receive service by the LA. The category recorded is that which fitted best at the point where the first assessment was carried out and, if there was difficulty choosing a single category, then the category highest in the list was used (this is the order 
shown in table 1). Children can have more than one episode of being a child in need and the request asked for the category given on the first episode. The category of abuse is allocated when a child is placed on a child protection plan. Children can be on a child protection plan more than once and the Fol asked for the category given at the start of the first plan for each child. Since not all agencies were able to answer all the different questions the table shows the number of LAs which replied to each question. The percentage of children born in 2009-10 was then calculated using the population of children in those LAs that replied.

\section{TABLE 1 ABOUT HERE}

\section{Discussion of results}

There are many issues raised by these Fol results. The $22.5 \%$ of all children referred to social care is likely to be concentrated in the areas of greatest deprivation as shown by the research of Bywaters et al. (2014a, b) discussed earlier. These children live in the most deprived areas where poverty, instability of housing, crime, poor health and many other stressors are common place. In these communities parents will experience higher than average levels of suspicion and investigation with the stigma and anxiety described above (Hooper et al., 2007). These issues will be considered further in a future paper. This paper focusses on the high proportion of children who are involved in children's services and the ineffectiveness of the system in reducing the need for this statutory intervention.

\section{High proportions of children involved in the child welfare system}

Table 1 shows that 111 of the 114 LAs provided data and 117,875 children were referred to children's services departments before their $5^{\text {th }}$ birthday, $22.5 \%$ of the estimated 521,688 
children in the 2009-10 cohort in these LAs. Thus more than 1 in every 5 children born in 2009-10 had concerns referred to children's services before the age of 5 .

What this study cannot answer is how many of these children and their parents actually received Early Help or responses other than assessment, investigation or care. Research by Thorpe et al. (2011) preceding much of the current focus on Early Help suggested that almost three-quarters of referred children did not receive services. They studied around 4,200 referrals in 14 LAs with each child followed for a year after referral. Only $19.5 \%$ of these referrals were initially treated as potentially being a child in need where CSC staff negotiated with parents about what help or advice was required. Other referrals were treated with an investigative orientation in which, for example, checks with other agencies were made without parental consent and in some cases joint visits were undertaken with the police. Not all of these cases were classified as formal child protection investigations though all were treated with a forensic orientation seeking to identify evidence. If this rate applied to the children in this study we would see around 95,000 children, $18 \%$ of all children, having experienced suspicion and an investigatively oriented response to referral. In their study $44.0 \%$ of all the referrals were offered services though mostly these 'were referred on to or "signposted" to other agencies" (Thorpe et al. 2011 p. 32) and the report states that the figures for take up of these services was probably over-estimated but well below this at "just over one quarter" (p.33) of referrals. Few of the referrals treated with an investigative orientation took up services. An Ofsted (2015) study of Early Help also found there was little follow-up on referred on/signposted services. Morrison (2010, pp.314-5) sums up how many parents feel about their engagement with children's social care which may explain the low level of service acceptance: 
Much is at stake for these families: fear of exposure, stigma, removal of their children or even prosecution. Fearful and anxious at the intrusion of external agencies, they may be defensive, angry and unwilling to acknowledge the reality of any difficulties. Negative previous experiences of statutory agencies may exacerbate this.

\section{Figure 3 about here}

Figure 3 shows the proportions reaching each stage of the children's service process before their fifth birthday. One in every six children had been assessed by children's services and more than one in every seven were considered to be in need and thus required services to achieve or maintain a reasonable standard of health or development. However, it cannot be assumed that these children, classified by the statistics as being in need, actually received services or help for their families. The most common reasons for children to be in need that social workers recorded were: 'Abuse and Neglect' (7.78\% of children born in 2009-10), which includes but is not limited to children formally investigated; and "Family dysfunction" (3.43\%) which includes "families where the low parenting capacity is at risk of, or actually is, impairing the child's health and development" and should "include children whose safety is in concern as a consequence of family dysfunction, but for whom there is not yet hard enough evidence to invoke child protection measures" (DfE 2015b p. 45). Thus social workers recorded their suspicion of abuse or neglect through these two categories for more than 1 in every 9 children born in 2009-10. However, in some cases where maltreatment is very minor and/or the response by family and others meet his/her needs, the child will not be recorded in these categories. Thus the $11.2 \%$ in these categories is an underestimate of the number of children found to be or suspected by social workers of being abused or neglected though more than half of this was below the threshold of concern about suspicion 
of significant harm that would trigger an investigation. Figure 3 also shows that $5.34 \%$ of children, more than 1 in every 19, were formally investigated under child protection legislation and $1.74 \%$ had spent some time in care.

To illustrate what this means, Figure 4 shows what involvement in the social care system would be found amongst children in an 'average' class of 30 with a fifth birthday in 2014-15. Seven of the 30 children would have been referred to CSC and four of these would have complex/multiple needs. Between one and two children would have been subject of a child protection investigation and one child found to be suffering or likely to suffer significant harm.

\section{Figure 4 about here}

As discussed above, over the period of this study there was a growing focus on Early Help intended to reduce the need for statutory involvement or entry to the child protection system. The Fol shows that three-quarters (76\%) of children who were referred reached the level of being assessed for statutory services and just under two-thirds (63\%) became a child in need. Thus a high proportion of referred children progressed, at some time, to the formal statutory system. This contrasts with the findings of the Committee on Education (2012 p. 5) which recommended research into whether "thresholds for section 17 and section 47 interventions are too high and/or rising in some area." Ironically during the period whilst this 'evidence' that thresholds for involvement of children's services were too high was being given to the committee, section 47 investigations rose by $25 \%$ in a single year whilst referrals fell by $1.6 \%$. However those giving this evidence may have been more concerned about the lack of help being offered to children as found by Thorpe et al. (2011). 
There is currently no way to ascertain the number of children at a national level receiving "Early Help" (Holmes et al. 2012 p. 16). It is thus not possible to ascertain how Early Help is being used and whether it is reaching out to a wider group still than the $22.5 \%$ referred. What is clear is that a high proportion of children are involved in statutory interventions despite the existence of these supposedly preventive measures and it is not known whether Early Help has contributed to rather than reduced this trend. This high level of statutory involvement and growing use of section 47 investigations indicates that the system has an increasingly forensic orientation (Hayes and Spratt, 2014). A worrying possibility is that Early Help has the unintended consequence of net-widening - drawing more children into this investigative maelstrom - and the concerns expressed by some parents that involvement in the Early Help system (Holmes et al. 2012 p. 8) "might lead to professionals across agencies making judgements about their parenting skills and subsequently result in a referral to children's social care" may be well founded.

One in every 16 children (6.2\%) was subject of a strategy discussion before reaching the age of 5 and thus thought to have been suffering or likely to suffer significant harm. The number formally investigated under section 47 was slightly lower at $5.4 \%$ ( 1 in every 19 children) and this is because some strategy discussions will provide information to assuage the suspicion that there is significant harm. One in 27 children (3.7\%) reached a child protection conference and one in 29 (3.5\%) were placed on a child protection plan. Thus $2.7 \%$ of all children, $43 \%$ of children reaching the stage of a strategy discussion, were not placed on a child protection plan before their fifth birthday having been formally suspected of abuse. Approaching half (45\%) of the occasions that a child was first placed on a child protection plan, and for $1.6 \%$ of all children, the category of abuse was neglect and for another quarter 
( $27 \%, 1.0 \%$ of children) it was emotional abuse. Physical abuse ( $16 \%$ and $0.5 \%$ of children) and sexual abuse ( $4 \%$ and $0.1 \%$ ) combined accounted for less than 1 in 5 of the child protection plans for this young group of children. These figures reflect the trends in the national statistics for children on child protection plans shown in figure 2 .

\section{Alternative non-blaming approaches}

Despite the lack of evidence that the child protection system reduces harm to young children (e.g. Gilbert at al., 2012) this investigative and blaming approach continues to increase and there are even calls by campaigning organisations such as the NSPCC for more children to be statutorily involved. The high incidence of suspicion shown by this study is likely to have "traumatic effects on families" (DoH, 1995 p.44) and create a climate of fear for those living in the poor communities (Hooper, 2007) where, as shown by Bywaters et al (2014a, b), higher rates of suspicion will be concentrated. Additionally, unless there has been a considerable improvement in recent years, a high proportion of those entering the system are not offered support; are signposted without help to access support; or do not accept support if it is offered (Thorpe et al., 2011).

The findings of this Fol add more weight to the arguments of those calling for a new paradigm for social work (e.g. Featherstone et al., 2014a). Developmental social work provides such an alternative paradigm with its focus on advocacy, poverty alleviation and developing family and community strengths (Midgley and Connley, 2010; Bilson and Larkins, 2013). It specifically aims to create "tangible improvements in standards of living, health and education, and a concomitant reduction in poverty, malnutrition, and illiteracy" (Midgley and Connley, 2010, p.13). This alternative orientation for CSC would aim to improve the conditions of families and communities enabling them to enhance the well- 
being of children rather than relying on agents of child protection to seek out harm. Its community orientation would allow it to embrace approaches such as "Strong Communities" that focuses on increasing neighbourhood cohesion to promote the wellbeing of children and families (McDonell et al., 2015); evidence-based approaches to early years education that increase social capital such as FAST (McDonald et al., 2015); and even advocating to increase incomes of poor families that on its own has been shown to increase the well-being of children (Cooper and Stewart, 2013).

\section{Conclusion}

This is the first study to show the extent that children are involved in children's social care over their first five years. This lack of longitudinal data in England is extremely worrying. The Fol request shows longitudinal data can easily be produced. Since it is vital to have an accurate picture of the child protection system in order to make policy, plan and assess services, government should make longitudinal data available annually. The findings also highlight the need for further research into the impact of Early Help on the wider child protection system, and the provision and outcomes of services for children referred to CSC.

This paper shows the high levels of suspicion of abuse and investigations and the increasing investigative orientation of the child protection system. Since $57 \%$ of referrals and $59 \%$ of child protection plans are on children aged 5 or older (DfE 2015 b), the proportion of children born in 2009-10 who are drawn into the statutory system will, before they reach the age of 18 , increase substantially above the $22.5 \%$ found here. Whilst some children need to be protected there is little evidence to support this scale of statutory involvement or the growing focus on early, and increasingly investigative, interventions alongside increases in removal of children from families into long-term care, special guardianship and adoption. 
These policies bring high levels of suspicion, fear and shame on a considerable proportion of families in the most deprived areas where this activity is concentrated. This is done without evidence that the individualised, investigative approach is effective in preventing further harm. Alternatives include a more humane developmental social work orientation and approaches that promote cohesion in neighbourhoods and reduce deprivation and poverty. But to achieve this we need to step away from our current preoccupation with the search for ever more parents to investigate and blame.

\section{Acknowledgements}

Many thanks to all the information officers who responded to our Freedom of Information request; to Brid Featherstone and Paul Bywaters for comments on early versions; and to the School of Social Work, Care and Community at the University of Central Lancashire for support for the research. 


\section{References}

Barnard, M. and Bain, C. (2015) 'Resisting your good intentions: substance-misusing parents and early intervention to support and monitor children in need', Child and Family Social Work, 20(2), pp. 171-180

Bilson A., Cant R., Harries M. and Thorpe D.H. (2016) “Accounting for the Increase of Children in Care in Western Australia: What can Client Information Systems Tell Us?” Manuscript in preparation

Bilson A., Cant R., Harries M. and Thorpe D.H. (2015) “A Longitudinal Study of Children Reported to the Child Protection Department in Western Australia." British Journal of Social Work 45 (3): 771-791

Bywaters, P., Brady, G., Sparks, T. and Bos, E. (2014a) 'Inequalities in child welfare intervention rates: the intersection of deprivation and identity', Child and Family Social Work, Advanced Access published June 2014, doi:10.1111/cfs.12161

Bywaters, P., Brady, G., Sparks, T. and Bos, E. (2014b) 'Child welfare inequalities: new evidence, further questions' Child and Family Social Work, Advanced Access published May 2014, doi:10.1111/cfs.12154

Cooper, K. and Stewart, K. (2013) Does Money Affect Children's Outcomes? A Systematic Review, York, Joseph Rowntree Foundation

Brown, R. and Ward, H. (2012) Decision-making within a child's timeframe, London, Childhood Wellbeing Research Centre, Institute of Education, second edition 
Davies, P. (2011) 'The impact of a child protection investigation: A personal reflective account', Child and Family Social Work, 16(2), 201-209.

DfE (2015a) Working together to safeguard children: A guide to inter-agency working to safeguard and promote the welfare of children, London, DfE. Available from https://www.gov.uk/government/uploads/system/uploads/attachment_data/file/41959 5/Working_Together_to_Safeguard_Children.pdf [Accessed 04/10/2015]

DfE (2015b) 'Characteristics of Children in Need: 2014 to 2015' London, DfE. Available from: https://www.gov.uk/government/uploads/system/uploads/attachment_data/file/46973 7/SFR41-2015_Text.pdf [Accessed: 11/11/2015]

Department of Health [DoH] (1995) Child protection: Messages from research, London: HMSO

Edwards, R., Gillies, V. and Horsley, N. (2015) ‘Brain science and early years policy: Hopeful ethos or 'cruel optimism?', Critical Social Policy, 35(2), 167-187.

Featherstone, B., White, S. and Morris, K. (2014a) Re-Imagining Child Protection: Towards Humane Social Work with Families, Bristol, Policy Press.

Featherstone, B., White, S. and Morris, K. (2014b) ‘A Marriage Made in Hell: Early Intervention Meets Child protection', British Journal of Social Work, 44, pp. 17351749

Frost, N. and Parton, N. (2009) Understanding Children's Social Care: Politics, Policy and Practice, London, SAGE 
Ghaffar, W., Manby, M. and Race, T. (2012) 'Exploring the experiences of parents and carers whose children have been subject to child protection plans', British Journal of Social Work, 42(5), pp. 887-905.

Gibson, M. (2013) 'Shame and guilt in child protection social work: new interpretations and opportunities for practice', Child and Family Social Work, 20(3), pp. 333-343

Gilbert R., Fluke J., O'Donnell M., Gonzalez-Izquierdo A., Brownell M., Gulliver P., Janson S. and Sidebotham P. (2012) 'Child maltreatment: variation in trends and policies in six developed countries', The Lancet, 379(9817), pp. 758-772.

Gilbert, N., Parton, N. and Skivenes, M. (2011) Child protection systems: International trends and orientations. Oxford, Oxford University Press.

Glaser, D., Prior, V., Auty, K. and Tilki, S. (2012) 'Does training in a systematic approach to emotional abuse improve the quality of children's services?' Available from: https://www.gov.uk/government/uploads/system/uploads/attachment_data/file /181602/DFE-RB196.pdf [Accessed 25/11/2015]

Gould, F., Clarke, J., Heim, C., Harvey, P. D., Majer, M. and Nemeroff, C. B. (2012) 'The effects of child abuse and neglect on cognitive functioning in adulthood', Journal of psychiatric research, 46(4), pp. 500-506.

Hayes, D. and Spratt, T. (2014) 'Child Welfare as Child Protection Then and Now: What Social Workers Did and Continue to Do', British Journal of Social Work, 44(3), pp. 615-635.

Holmes, L., McDermid, S., Padley, M. and Soper, J. (2012) Exploration of the costs and impact of the Common Assessment Framework, London, DfE. 
Hooper, C. A., Gorin, S., Cabral, C. and Dyson, C. (2007) Living with hardship 24/7: the diverse experiences of families in poverty in England, Frank Buttle Trust.

House of Commons Education Committee (2012) Children first: the child protection system in England Fourth Report of Session, 13, 8. Available from http://www.publications.parliament.uk/pa/cm201213/cmselect/cmeduc/137/137.pdf [Accessed 12/10/2015]

London Children's Safeguarding Board (undated) Threshold Document: Continuum of Help and Support; London, London Children's Safeguarding Board. Available from http://www.londoncp.co.uk/files/revised_guidance_thresholds.pdf [Accessed $14 / 01 / 2016]$

Luckock, B., Barlow, J. and Brown, C. (2015) 'Developing innovative models of practice at the interface between the NHS and child and family social work where children living at home are at risk of abuse and neglect: a scoping review', Child and Family Social Work Advanced Access published March, 16, 2015, doi:10.1111/cfs.12228

Magruder, J. and Shaw, T. V. (2008) 'Children ever in care: An examination of cumulative disproportionality', Child welfare, 87(2), pp. 169-188.

McDonald, L., Miller, H. and Sandler, J. (2015) ‘A social ecological, relationship-based strategy for parent involvement: Families And Schools Together (FAST)', Journal of Children's Services, 10(3), 218-230. 
McDonell, J. R., Ben-Arieh, A. and Melton, G. B. (2015) 'Strong Communities for Children: Results of a multi-year community-based initiative to protect children from harm', Child abuse and neglect, 41, pp. 79-96.

Midgley, J. and Conley, A. (Eds.) (2010) Social work and social development: Theories and skills for developmental practice, New York: Oxford University Press.

Mikton, C. and Butchart, A. (2009) 'Child maltreatment prevention: a systematic review of reviews', Bulletin of the World Health Organization, 87(5), pp. 353-361.

Morrison, T. (2010) 'Assessing parental motivation for change.' In J. Horwath (ed) The Child's World: The Comprehensive Guide to Assessing Children in Need, London, Jessica Kingsley Publishers.

Munro, E. (2011). The Munro Review of Child Protection: Final Report-a Child-centred Approach (Vol. 8062), The Stationery Office.

Munro, E. and Manful, E. (2012) Safeguarding children: a comparison of England's data with that of Norway and the United States Sheffield, Department for Education (DfE). Available from: https://www.gov.uk/government/uploads/system/uploads/attachment_data/file /197718/DFE-RB198_1_.pdf [Accessed: 11/11/2015]

Norman, R. E., Byambaa, M., De, R., Butchart, A., Scott, J. and Vos, T. (2012) 'The long-term health consequences of child physical abuse, emotional abuse, and neglect: a systematic review and meta-analysis', PLOS Medicine 9(11), pp. 1-32 Available from 
http://journals.plos.org/plosmedicine/article?id=10.1371/journal.pmed.1001349 [Accessed 23/11/2015]

Office for National Statistics (2014) Annual Mid-year Population Estimates, 2013, Available from: http://www.ons.gov.uk/ons/rel/pop-estimate/population-estimates-for-uk-england-and-wales--scotland-and-northern-ireland/2013/stb---mid-2013-ukpopulation-estimates.html [Accessed 05/05/2015]

Ofsted (2015) Early Help: whose responsibility? Manchester, Ofsted. Available from: https://www.gov.uk/government/uploads/system/uploads/attachment_data/file/41037 8/Early_help_whose_responsibility.pdf [Accessed 21/11/2015]

Parton, N. (2014) 'Social work, child protection and politics: Some critical and constructive reflections', British Journal of Social Work, 44(7), pp. 2042-2056.

Peckover, S. (2014) 'Domestic abuse, safeguarding children and public health: towards an analysis of discursive forms and surveillant techniques in contemporary UK policy and practice', British Journal of Social Work, 44(7), pp. 1770-1787.

Platt, D. and Turney, D. (2014) 'Making threshold decisions in child protection: a conceptual analysis', British Journal of Social Work, 44(6), pp. 1472-1490.

Scott, D. (2014) 'Children in Australia: Harms and hopes', Family Matters, 96, pp.14-22

Sidebotham, P., Heron, J., Golding, J. (2002). 'Child maltreatment in the "Children of the Nineties:" deprivation, class, and social networks in a UK sample', Child abuse and neglect, 26(12), pp. 1243-1259. 
Thorpe D., Denman G. and Regan S. (2011) RIEP and ACDS Funded Safeguarding and Promoting Welfare Research Project, Kendal, Practice Research Overbeck.

Thorpe, D., Regan, S., Mason, C. and May-Chahal, C. (2012) 'Making a case for common assessment framework responses to concerns about children', Social Work and Social Sciences Review, 12(3), pp. 40-56.

Trocmé, N., Kyte, A., Sinha, V. and Fallon, B. (2014) 'Urgent protection versus chronic need: clarifying the dual mandate of child welfare services across Canada', Social Sciences, 3(3), pp. 483-498.

Wastell, D. and White, S. (2012) 'Blinded by neuroscience: social policy, the family and the infant brain' Families, Relationships and Societies, 1(3), pp. 397-414(18). 
Figure Legend

Figure 1: Increasing investigative response to referrals 2009-10 to 2014-15. This figure draws on annual statistical returns to show a graph of the number of the annual number of children investigated under section 47 and the number of child starting a child protection plan. It also shows a table giving the proportion of referrals and children in need who were subject to a child protection investigation.

Figure 2: Increasing use of Child Protection Plans following Neglect and Emotional Abuse. This figure draws on national statistics to show a graph of the number of children on a child protection plan at $31^{\text {st }}$ March showing the type of neglect or abuse that led to the plan.

Figure 3: Proportions involved in children's social care. This figure uses findings of the Freedom of Information request to show the proportion of children born in 2009-10 who reached each stage of the children child protection system before reaching the age of 5 .

Figure 4: Referrals and investigations in an 'average' class of 30 five-year olds. This figure illustrates the proportions of children reaching different stages of the child protection system if the results of the Freedom of Information request were seen in an 'average' class of 30 children. 
Table 1: Results of the Freedom of Information Request showing number and percent of children born between April $1^{\text {st }} 2009$ and 31st March 2010 who had reached various stages of the children's services before their $5^{\text {th }}$ birthday.

\begin{tabular}{|c|c|c|c|}
\hline & $\begin{array}{l}\text { Percentage of } \\
\text { all children } \\
\text { born } 2009-10^{\dagger}\end{array}$ & $\begin{array}{l}\text { Number } \\
\text { of children }\end{array}$ & $\begin{array}{l}\text { Number of } \\
\text { LAs } \\
\text { providing } \\
\text { data" }\end{array}$ \\
\hline 1. Children referred & $22.5 \%$ & 115,735 & 111 \\
\hline 2. Children assessed by Children's Services & $17.0 \%$ & 83,713 & 106 \\
\hline 3. Children in need & $14.3 \%$ & 72,181 & 108 \\
\hline \multicolumn{4}{|l|}{ Primary Need Code on the first episode as a Child in Need } \\
\hline N1 Abuse or neglect & $7.8 \%$ & 38,365 & 102 \\
\hline N2 Child's disability & $0.6 \%$ & 2,737 & 101 \\
\hline N3 Parental disability or illness & $0.5 \%$ & 2,404 & 99 \\
\hline N4 Family in acute stress & $1.8 \%$ & 8,775 & 102 \\
\hline N5 Family dysfunction & $3.3 \%$ & 16,084 & 102 \\
\hline N6 Socially unacceptable behaviour & $0.2 \%$ & 1,001 & 100 \\
\hline N7 Low Income & $0.1 \%$ & $80 *$ & 24 \\
\hline N8 Absent parenting & $0.1 \%$ & $52 *$ & 21 \\
\hline 4. Children subject of a strategy discussion & $6.2 \%$ & 29,895 & 104 \\
\hline 5. Children subject of a section 47 enquiry & $5.4 \%$ & 27,794 & 111 \\
\hline 6. Children subject of a child protection conference & $3.7 \%$ & 19,014 & 110 \\
\hline 7. Children subject of a child protection plan & $3.5 \%$ & 17,823 & 111 \\
\hline \multicolumn{4}{|c|}{ Category of abuse as recorded when the first child protection plan commenced } \\
\hline a) Neglect & $1.6 \%$ & 7,721 & 105 \\
\hline b) Physical Abuse & $0.5 \%$ & 2,662 & 103 \\
\hline c) Sexual Abuse & $0.1 \%$ & 633 & 103 \\
\hline d) Emotional Abuse & $1.0 \%$ & 4,701 & 104 \\
\hline e) Multiple/Not recommended & $0.3 \%$ & 1,272 & 104 \\
\hline 8. Children subject of a supervision order & $0.3 \%$ & 1,010 & 78 \\
\hline 9. Children subject of a care order & $1.1 \%$ & 5,312 & 107 \\
\hline 10. Children ever having been looked after [in care] & $1.7 \%$ & 8,929 & 111 \\
\hline \multicolumn{4}{|c|}{$\begin{array}{l}\text { Notes } \\
+\quad \text { This is the percentage of children in the local authorities that provided data } \\
\# \quad \text { This is the number of local authorities that provided data for this question } \\
* \quad \text { There are many returns in this category with less than } 5 \text { children and the total is } \\
\text { estimated }\end{array}$} \\
\hline
\end{tabular}




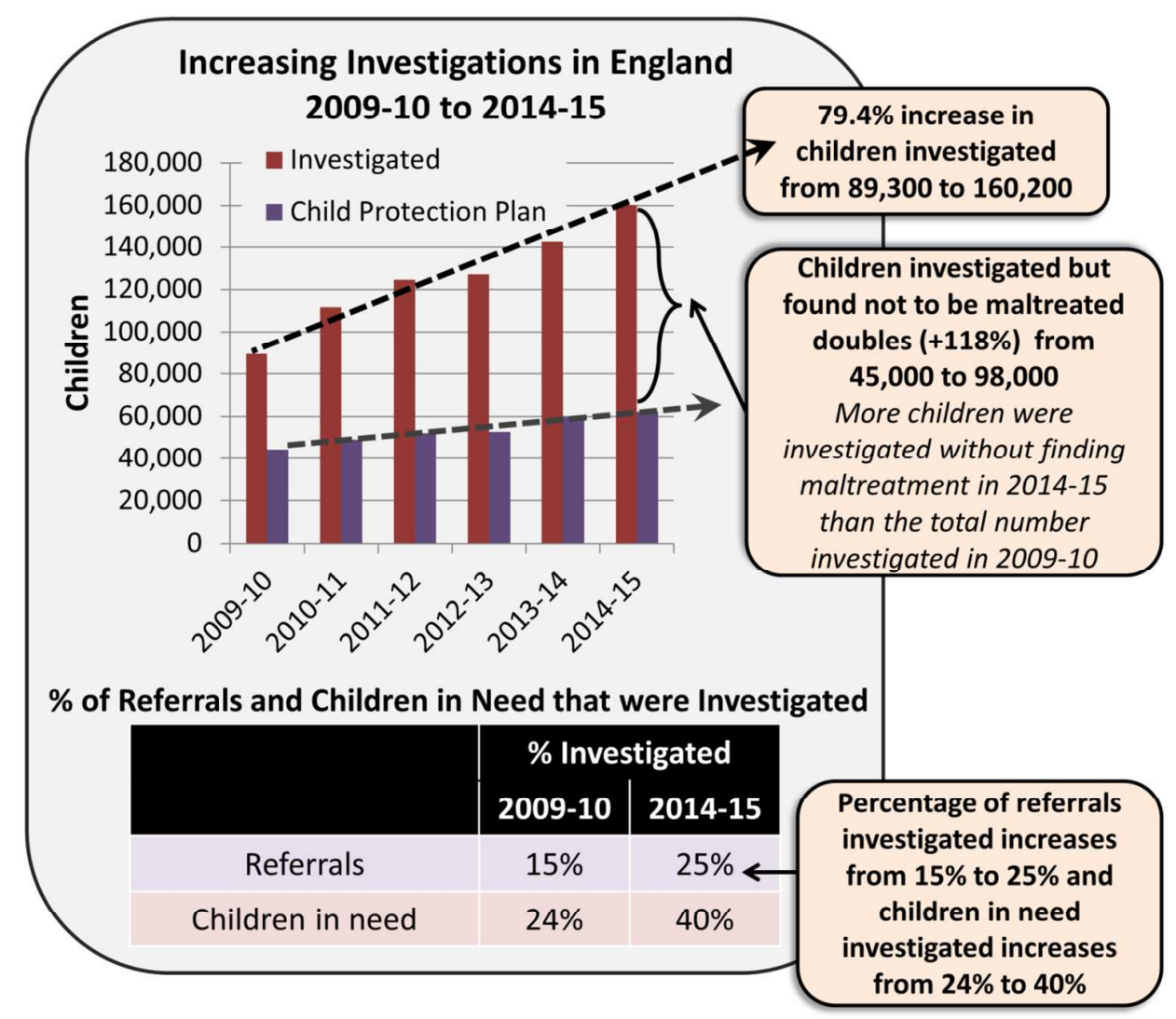

Figure 1: Increasing investigative response to referrals 2009-10 to 2014-15 $129 \times 112 \mathrm{~mm}(300 \times 300 \mathrm{DPI})$ 


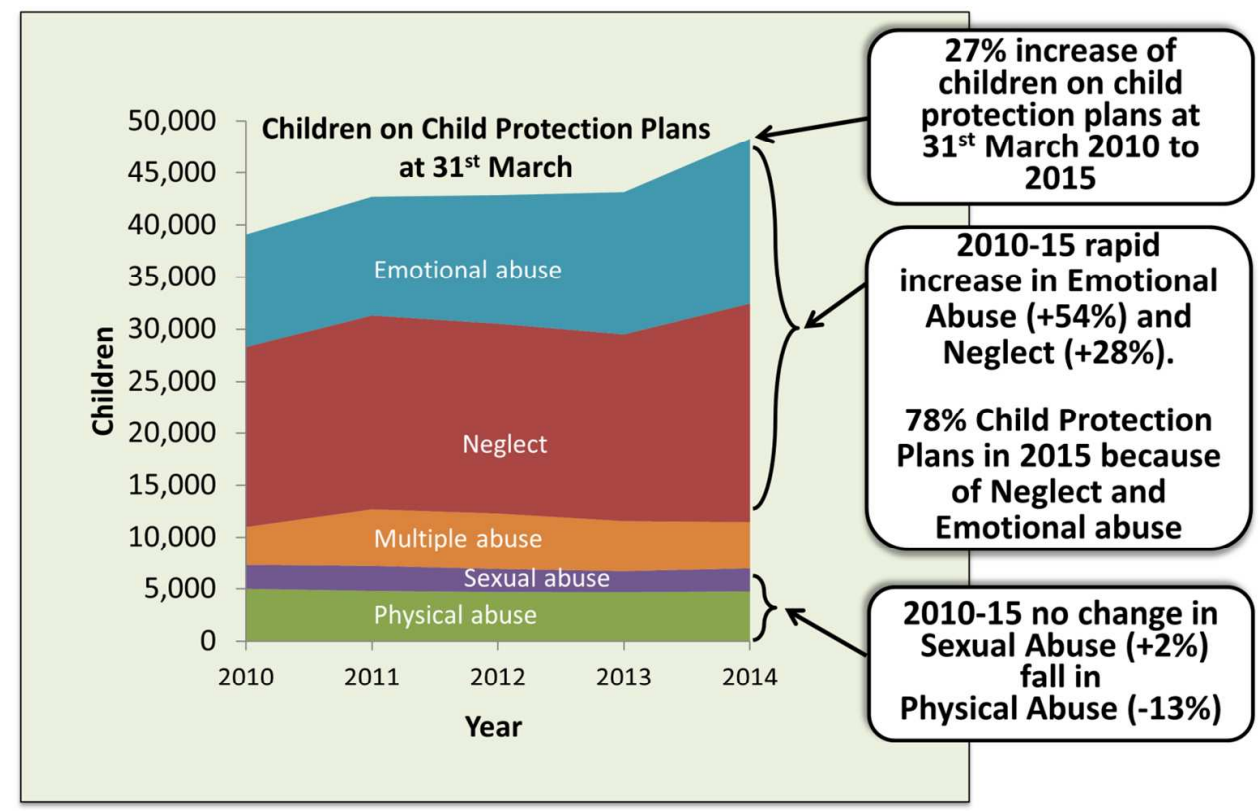

Figure 2: Increasing use of Child Protection Plans following Neglect and Emotional Abuse $129 \times 83 \mathrm{~mm}(300 \times 300 \mathrm{DPI})$ 


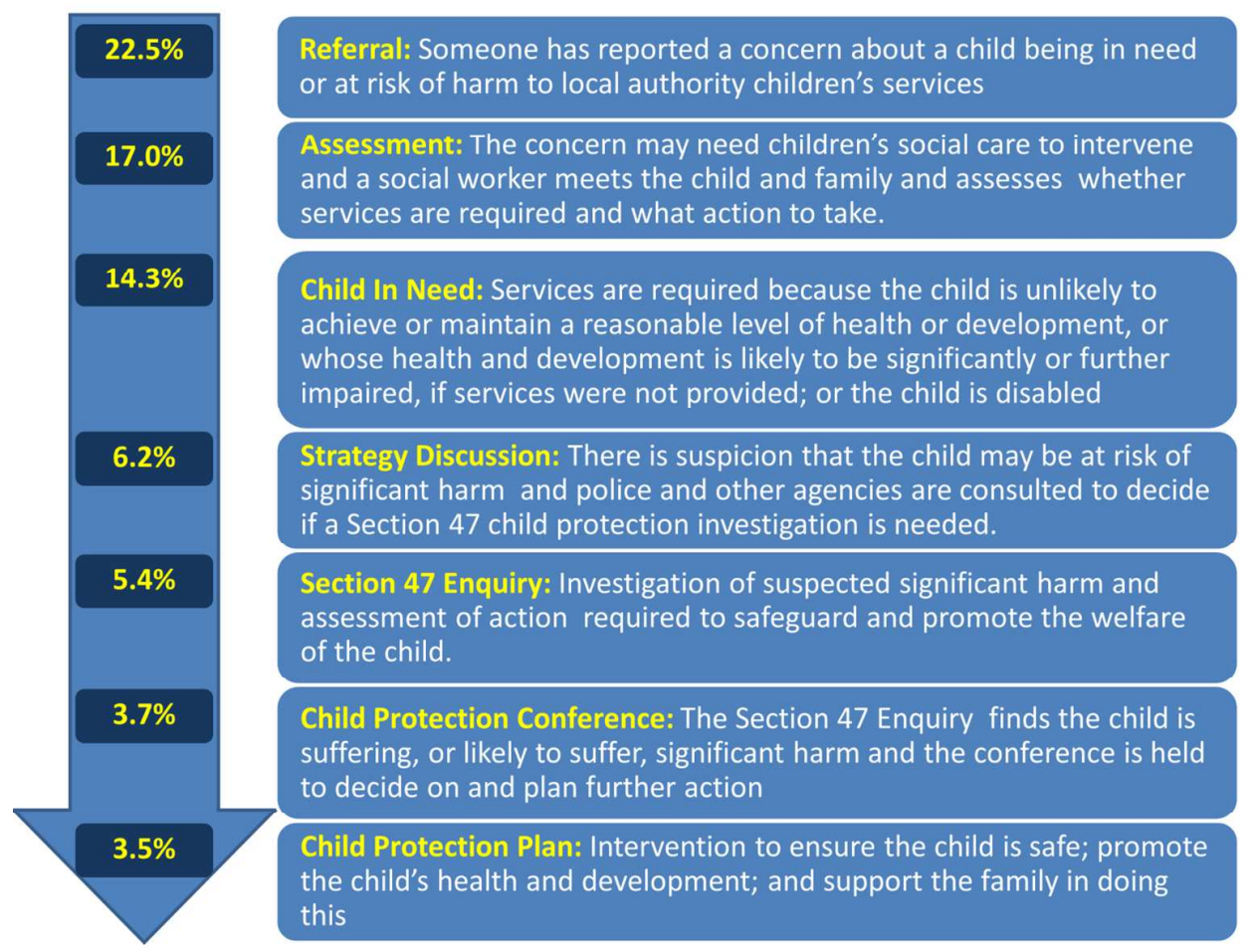

Figure 3: Proportions involved in children's social care $129 \times 97 \mathrm{~mm}(300 \times 300 \mathrm{DPI})$ 


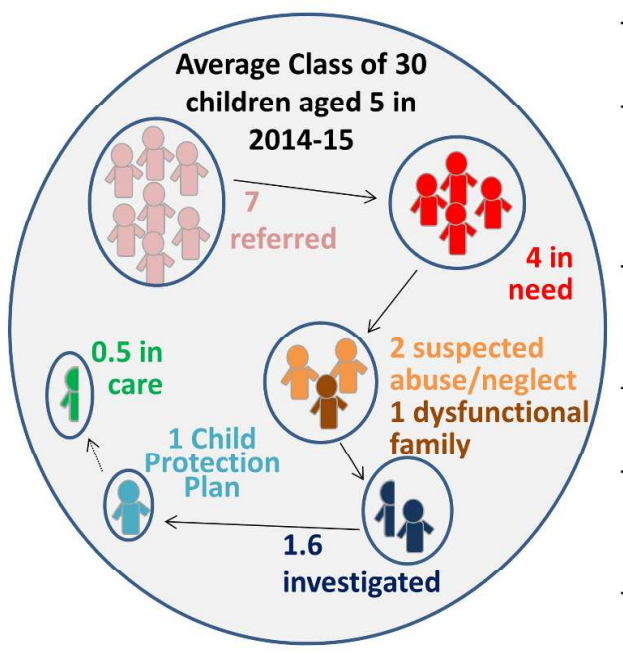

$\rightarrow$ Seven children: referred to children's services

$\rightarrow$ Four referred children: required services to achieve or maintain a reasonable standard of health or development (i.e. they were 'in need')

$\rightarrow$ Three children in need: suspected of being abused or neglected ( 2 abuse or neglect and 1 dysfunctional family)

$\rightarrow 1.6$ children: (1 or 2 in each class) formally investigated for suspected abuse

$\rightarrow$ One child: suffering, or likely to suffer, significant harm (i.e. on a child protection plan)

$\rightarrow 1 / 2$ child: (one child in every other class) would have been in care.

Figure 4: Referrals and investigations in an 'average' class of 30 five-year olds $254 \times 139 \mathrm{~mm}(300 \times 300$ DPI $)$ 